OPEN ACCESS

Edited by:

Fatima Nasrallah,

The University of Queensland,

Australia

Reviewed by:

Xuemin Xu,

The University of Tennessee,

Knoxville, United States

Eirini Lionaki,

Foundation for Research and Technology Hellas, Greece

*Correspondence:

Xijin Wang

wangxijin@xinhuamed.com.cn;

ychwjs2004@163.com

tThese authors have contributed equally to this work.

Received: 12 April 2017 Accepted: 17 October 2017 Published: 03 November 2017

Citation:

Yang $L$, Chen $Z$, Li B, Wang $M, Y u L$, Wan Y, Gan J, Zhang Y, Liu Z and Wang $X$ (2017) Multiple Evidences for Association between Cognitive Impairment and Dysglycemia in Parkinson's Disease: Implications for Clinical Practice.

Front. Aging Neurosci. 9:355. doi: 10.3389/fnagi.2017.00355

\section{Multiple Evidences for Association between Cognitive Impairment and Dysglycemia in Parkinson's Disease: Implications for Clinical Practice}

\author{
Liu Yang ${ }^{1 \dagger}$, Zhilin Chen ${ }^{1+}$, Bo Li ${ }^{2+}$, Meihua Wang ${ }^{1}$, Lijia Yu1, Ying Wan ${ }^{1}$, Jing Gan', \\ Yu Zhang ${ }^{1}$, Zhenguo Liu' ${ }^{1}$ and Xijin Wang ${ }^{1 *}$ \\ 1 Department of Neurology, Xinhua Hospital, Shanghai Jiao Tong University School of Medicine, Shanghai, China, \\ ${ }^{2}$ Department of Endocrinology, Xinhua Hospital, Shanghai Jiao Tong University School of Medicine, Shanghai, China
}

Background and purpose: It remains unclear about the etiopathogenesis of cognitive impairment $(\mathrm{Cl})$ in Parkinson's disease (PD). Since diabetes mellitus (DM) has been shown to be associated with $\mathrm{Cl}$ in several diseases, we examined the association between $\mathrm{Cl}$ and dysglycemia in PD.

Methods: Enrolled PD patients completed a series of clinical and neuropsychological assessments. Motor symptoms were determined by Hohen-Yahr staging $(\mathrm{H}-\mathrm{Y}$ staging) and Unified Parkinson's Disease Rating Scale - motor score (UPDRS-III). Neuropsychological functions were evaluated by the Mini Mental State Examination (MMSE), the Montreal Cognitive Assessment (MoCA), and the Hamilton Anxiety and Depression Scales. Moreover, fasting glucose, fasting insulin, glycosylated hemoglobin $\mathrm{A} 1 \mathrm{c}(\mathrm{HbA} 1 \mathrm{c})$ and oral glucose tolerance test were performed to assess glucose metabolism.

Results: MoCA and MMSE scores in PD patients with DM group (PD-DM) were significantly lower than those in PD patients without DM group (PD-nDM). Consistently, PD-DM group showed significantly higher constituent ratio of $\mathrm{Cl}$ than PD-nDM group. In addition, MoCA scores in $\mathrm{HbA} 1 \mathrm{c} \geq 6.5 \%$ group and $\mathrm{HbA} 1 \mathrm{c} \geq 7 \%$ group were significantly lower than those in the corresponding control groups. MoCA score in $\mathbb{R} \geq 3$ group was significantly lower than that in $\mathbb{R}<3$ group. Furthermore, MoCA score was negatively correlated with $\mathrm{H}-\mathrm{Y}$ staging, $\mathrm{HbA} 1 \mathrm{c}$ and insulin resistance, respectively. Finally, regression analysis indicated that $\mathrm{H}-\mathrm{Y}$ staging and $\mathrm{HbA} 1 \mathrm{C} \geq 7 \%$ were independent risk factors of $\mathrm{Cl}$ in PD.

Conclusion: $\mathrm{Cl}$ may be tightly associated with dysglycemia in, at least partially, PD patients. Importantly, $\mathrm{H}-\mathrm{Y}$ staging and $\mathrm{HbA} 1 \mathrm{c} \geq 7 \%$, two independent risk factors of $\mathrm{Cl}$ in $\mathrm{PD}$, may serve as key biomarkers in future $\mathrm{PD}$ clinical practice.

Keywords: cognitive impairment, dysglycemia, Parkinson's disease, glycosylated hemoglobin A1c, risk factors 


\section{INTRODUCTION}

Parkinson's disease (PD) has been recognized as a multisystem neurodegenerative disorder with typical motor symptoms, including static tremor, bradykinesia, rigidity, postural instability, and gait difficulty. Although movement symptoms are the main clinical characteristics of $\mathrm{PD}$, increasing evidence has shown that PD patients often experience a series of non-motor symptoms, including cognitive impairment (CI), dysfunction of autonomic nervous system, and behavioral disturbances.

Cognitive dysfunction is one of the most devastating and common non-motor symptoms of PD. There are approximately $20-40 \%$ of patients suffering from CI in the early stage of PD (Aarsland et al., 2010). The average incidence of mild CI has shown to be $26.7 \%$ (range, 18.9-38.2\%) in PD (Litvan et al., 2011). More than $75-80 \%$ of the patients will eventually develop to dementia (Litvan et al., 2011). The cumulative incidence of dementia in PD approached to $80 \%$ in a community-based study (Hely et al., 2008). A prospective study suggested that individuals with PD had a three-suxfold higher risk of developing dementia than people without PD at the same age (Aarsland et al., 2001). PD severely impacts on the patients' life quality, imposing a huge burden on the patients, their family and society. CI makes this hard situation even worse in PD patients.

According to a nationally cross-sectional survey in China, the overall prevalence of diabetes mellitus (DM) was estimated to be $11.6 \%$ in the Chinese adult population (Xu et al., 2013). Diabetes is frequently accompanied with a variety of complications. Many studies have shown a relationship between diabetes and cognitive decline, and this correlation is particularly significant in patients over 60 years old (Xu et al., 2009). Several epidemiological studies have suggested that diabetes is associated with the development of PD. For example, diabetes has been shown to be one risk factor for the occurrence of PD (Cereda et al., 2011). Diabetes may aggravate movement symptoms of PD patients (Cereda et al., 2012; Kotagal et al., 2013).

However, little is known about the association between CI and dysglycemia in PD. Therefore, in the present study, we investigated the association between cognitive function and dysglycemia in PD with the following aims: to compare clinical characteristics of Parkinson's disease patients with (PD-DM) or without (PD-nDM) diabetes mellitus, to compare cognitive function at different levels of HbAlc and insulin resistance in Parkinson's disease patients, and finally to investigate risk factors of CI in Parkinson's disease.

\section{MATERIALS AND METHODS}

\section{Participants}

A total of 282 PD patients were recruited in the department of Neurology at Xinhua hospital affiliated to Shanghai Jiao Tong University from October 2013 to October 2016. All the participants were examined by a movement disorder neurologist

TABLE 1 | Clinical characteristics of PD-DM and PD-nDM patients.

\begin{tabular}{|c|c|c|c|}
\hline & $\begin{array}{l}\text { PD-nDM } \\
(n=197)\end{array}$ & $\begin{array}{l}\text { PD-DM } \\
(n=85)\end{array}$ & $P$ \\
\hline Gender (male: number/percentage) & $108 / 54.8 \%$ & $44 / 51.8 \%$ & $0.697^{\mathrm{C}}$ \\
\hline Duration (year) & $5.02 \pm 5.48$ & $5.05 \pm 5.22$ & $0.430^{\mathrm{b}}$ \\
\hline Onset age (year) & $64.08 \pm 9.46$ & $65.74 \pm 8.12$ & $0.171^{\mathrm{a}}$ \\
\hline Current smoking (number/percentage) & $65 / 33.0 \%$ & $23 / 27.1 \%$ & $0.332^{\mathrm{C}}$ \\
\hline \multicolumn{4}{|l|}{ Form of onset } \\
\hline Tremor (number/percentage) & $114 / 57.9 \%$ & $42 / 49.4 \%$ & $0.195^{\mathrm{C}}$ \\
\hline Dominant side involved (number/percentage) & $103 / 52.3 \%$ & $50 / 58.8 \%$ & $0.362^{\mathrm{C}}$ \\
\hline \multicolumn{4}{|l|}{ Drugs } \\
\hline Levodopa intake (number/percentage) & $177 / 89.8 \%$ & $80 / 94.1 \%$ & $0.268^{\mathrm{C}}$ \\
\hline COMTI (number/percentage) & $5 / 2.5 \%$ & $5 / 5.9 \%$ & $0.291^{c}$ \\
\hline \multicolumn{4}{|l|}{ Movement symptoms } \\
\hline UPDRS-III & $21.91 \pm 13.85$ & $23.78 \pm 14.41$ & $0.279^{b}$ \\
\hline $\mathrm{H}-\mathrm{Y}$ staging & & & $0.126^{\mathrm{C}}$ \\
\hline 0-1 (number/percentage) & $65 / 33.0 \%$ & $18 / 21.2 \%$ & \\
\hline 1.5-2 (number/percentage) & $73 / 37.1 \%$ & $39 / 45.9 \%$ & \\
\hline 2.5-3 (number/percentage) & $59 / 29.9 \%$ & $28 / 32.9 \%$ & \\
\hline
\end{tabular}

PD-nDM, Parkinson's disease patients without diabetes mellitus; PD-DM, Parkinson's disease patients with diabetes mellitus; DRA, dopamine receptor agnoists; MAOBI, Monoamine oxidase type B inhibitors; COMTI, Catechol-O-methyltransferase inhibitors; UPDRS-III, Unified Parkinson's Disease Rating Scale motor score; H-Y staging, Hohen-Yahr staging; atwo-sample t- test; ${ }^{\mathrm{b}}$ Mann-Whitney U-test; ${ }^{\mathrm{c}}$ Chi-square test. 

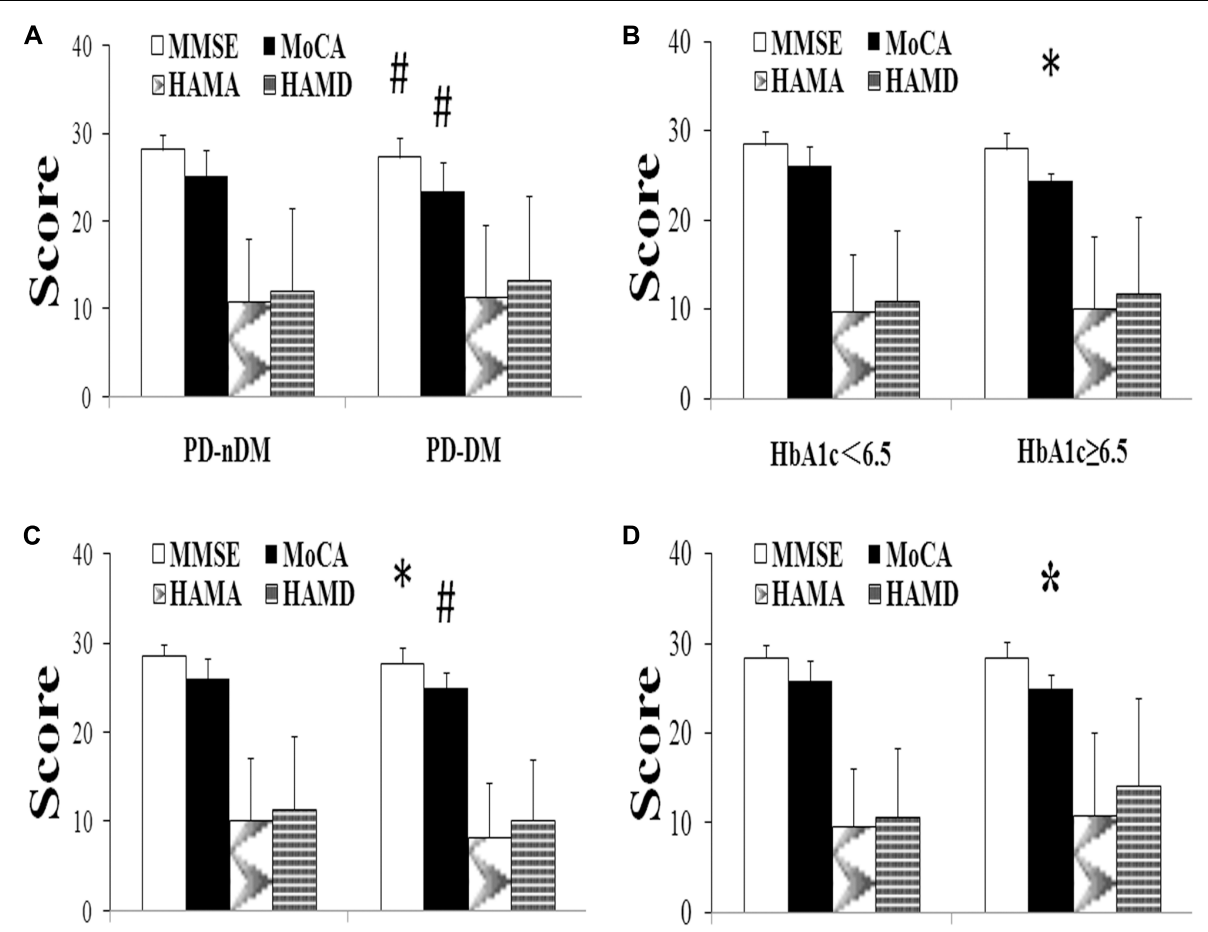

$\operatorname{HbAlc<7} \quad \mathrm{HbAlc} \geq 7$

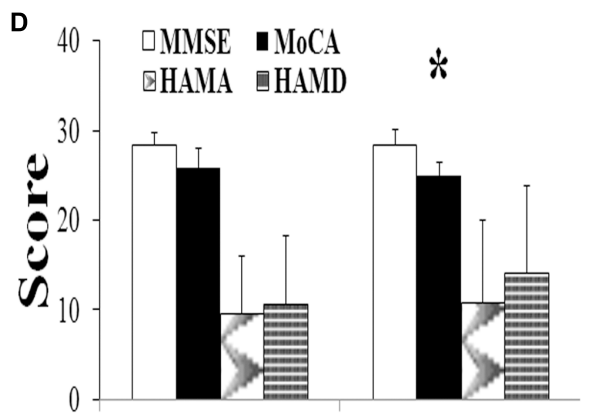

$\mathrm{IR}<3 \quad \mathrm{IR}>3$

FIGURE 1 | Neuropsychological assessment in Parkinson's disease (PD). (A) Comparison of neuropsychological function of PD patients with (PD-DM, $n=85$ ) or without (PD-nDM, $n=197$ ) diabetes mellitus. (B) Comparison of neuropsychological function of PD patients with HbA1c $<6.5(n=90)$ or $\mathrm{HbA} 1 \mathrm{c} \geq 6.5(n=29)$. (C) Comparison of neuropsychological function of PD patients with $\mathrm{HbA1c}<7(n=95)$ or $\mathrm{HbA1c} \geq 7(n=24)$. (D) Comparison of neuropsychological function of PD patients with IR $<3(n=104)$ or $I R \geq 3(n=15)$. HbA1c, glycosylated hemoglobin A1c; IR, insulin resistance; MMSE, Mini Mental State Examination; MoCA, Montreal Cognitive Assessment; HAMA, Hamilton Anxiety Scale; HAMD, Hamilton Depression Scale. ${ }^{*} p<0.05$, compared with the corresponding control group; $\# p<0.01$, compared with the corresponding control group.

and met United Kingdom PD Society Brain Bank Research Center clinical criteria, and completed a series of clinical and neuropsychological assessment at the "on" status. The exclusion criteria were (1) patients with parkinsonism syndrome secondary to drugs, cerebrovascular disease, encephalitis, metabolic disease except diabetes, malignant tumor, carbon monoxide poisoning, or any other neurological and psychiatric disorders; (2) patients had prior or planned neurosurgical treatment (e.g., deep brain stimulation); (3) patients had anticholinergic medications (e.g., trihexyphenidyl, memantine); other medical or neurological causes of CI (e.g., seizures, strokes, head trauma, and neurosyphilis); (4) patients suffered from a serious chronic physical disease or diseases that affect glucose metabolism (e.g., cardiac insufficiency, renal failure, thyroid dysfunction) and; (5) patients with fasting glucose $<3.9 \mathrm{mmol} / \mathrm{L}$; (6) patients were unable to complete the questionnaire. This study was carried out in accordance with the recommendations of the Ethics Committee of Xinhua Hospital affiliated to Shanghai Jiao Tong University School of Medicine with written informed consent from all patients or their legal guardians. All patients or their legal guardians were given the informed consent form in accordance with the Declaration of Helsinki. The protocol was approved by the Ethics Committee of Xinhua Hospital affiliated to Shanghai Jiao Tong University School of Medicine.

\section{Clinical Data Collection}

The detailed demographics characteristics of study participants included age, gender, body mass index (BMI), diseaserelated variables, medications, and educational background (measured as the total number of school years). All the participants underwent Hohen-Yahr staging ( $\mathrm{H}-\mathrm{Y}$ staging) and Unified Parkinson's Disease Rating Scale - motor score (UPDRS-III) to evaluate motor symptoms. All participants underwent neuropsychological assessment by an experienced neuropsychologist. General cognitive function was measured using the Mini Mental State Examination (MMSE), which has a maximum score of 30 . Dementia severity was assessed

TABLE 2 | Comparison of constituent ratio of cognitive impairment (Cl) in PD-nDM and PD-DM patients.

\begin{tabular}{lccc}
\hline & PD-nDM & PD-DM & P \\
& $(\boldsymbol{n}=\mathbf{1 9 7 )}$ & $(\boldsymbol{n}=\mathbf{8 5})$ & \\
\hline $\mathrm{PD}-\mathrm{nCl}$ & $110 / 55.8 \%$ & $22 / 25.9 \%$ & $\mathbf{0 . 0 0 0 ^ { \mathbf { c } }}$ \\
$\mathrm{PD}-\mathrm{Cl}$ & $87 / 44.2 \%$ & $63 / 74.1 \%$ & \\
\hline
\end{tabular}

$P D-n D M, P D$ patients without diabetes mellitus; $P D-D M, P D$ patients with diabetes mellitus; $P D-n C l, P D$ patients without cognitive impairment; $P D-C l, P D$ patients with cognitive impairment. ${ }^{\mathrm{C}}$ Chi-square test. 
using Montreal Cognitive Assessment (MoCA), which includes the following seven domains: visuospatial/executive $\left(5^{\prime}\right)$, naming $\left(3^{\prime}\right)$, delayed memory $\left(5^{\prime}\right)$, attention $\left(6^{\prime}\right)$, language $\left(3^{\prime}\right)$, abstraction $\left(2^{\prime}\right)$, and orientation $\left(6^{\prime}\right)$. If the informed years of education were $\leq 12$ years, then $1^{\prime}$ was added to correct the bias for education level. Patients with MoCA scores $<26^{\prime}$ were considered to have CI (Dalrymple-Alford et al., 2010; Litvan et al., 2012; Marras et al., 2013). Emotion evaluations were based on Hamilton Anxiety Scale (HAMA, 14 items) and Hamilton Depression Scale (HAMD, 24 items) (Hamilton, 1967; Xiao et al., 2011; Kandiah et al., 2014).

\section{Biochemical Tests}

Biochemical tests for fasting glucose, HbAlc, fasting insulin and oral glucose tolerance test (OGTT) were performed in 119 participants. Procedure for $2 \mathrm{~h}-\mathrm{OGTT}$ required administration of $75 \mathrm{~g}$ oral glucose load within a 5-min period, and 2-h postprandial glucose was subsequently drawn at $120 \mathrm{~min}$, timed from the beginning of the glucose load ( $\mathrm{Hu}$ et al., 2004; Cukierman-Yaffe et al., 2009; Bosco et al., 2012; Cereda et al., 2012; Yaffe et al., 2012). A fasting glucose $\geq 6.1 \mathrm{mmol} / \mathrm{L}$ was considered as high fasting glucose (Hu et al., 2004; Cukierman-Yaffe et al., 2009; Cereda et al., 2012; Yaffe et al., 2012). Patients were considered to have an impaired glucose tolerance (IGT) if 2-h postprandial glucose was between 7.8 and $11.1 \mathrm{mmol} / \mathrm{L}$ (Hu et al., 2004; CukiermanYaffe et al., 2009; Cereda et al., 2012; Yaffe et al., 2012). Insulin resistance (IR) was calculated by the homoeostasis model assessment (HOMA) formula [HOMA-Index: Basal Glucose Plasma $(\mathrm{mmol} / \mathrm{L}) \times$ Basal Insulin Plasma $(\mathrm{mU} / \mathrm{L}) / 22.5]$ (Matthews et al., 1985; Bosco et al., 2011, 2012). Patients were considered to have insulin resistance if their HOMAIndexes $\geq 3$ (Matthews et al., 1985). DM was defined by one of the following criteria: participants reported diabetes history, discharge diagnosis of DM, a tested fasting glucose level higher than $7.0 \mathrm{mmol} / \mathrm{L}$, or a 2-h postprandial glucose level higher than $11.1 \mathrm{mmol} / \mathrm{L}$ (Boon et al., 1997; Hu et al., 2004; Cukierman-Yaffe et al., 2009; Cereda et al., 2012; Yaffe et al., 2012).

\section{Statistical Analyses}

All statistical procedures were conducted using Statistical Package for the Social Sciences (SPSS) version 20.0 for Windows. Comparison between groups was performed using a twosample $t$-test (normal distribution) or Mann-Whitney $U$-test (abnormal distribution) as appropriate. Categorical variables were examined using the Chi-square test. Correlation tests were performed using spearman correlation analysis, and the statistically significant indicators were included in the logistic regression analysis. Statistical significance was set at $p<0.05$.

TABLE 3 | Clinical characteristics of $\mathrm{HbA} 1 \mathrm{c}<6.5$ and $\mathrm{HbA1c} \geq 6.5$ groups in $\mathrm{PD}$.

\begin{tabular}{|c|c|c|c|}
\hline & $\begin{array}{c}\text { HbA1c }<6.5 \\
(n=90)\end{array}$ & $\begin{array}{c}\mathrm{HbA} 1 \mathrm{c} \geq 6.5 \\
(n=29)\end{array}$ & $P$ \\
\hline Gender (male: number/percentage) & $51 / 56.7 \%$ & $15 / 51.7 \%$ & $0.672^{\mathrm{c}}$ \\
\hline Duration (year) & $4.15 \pm 4.18$ & $4.59 \pm 3.21$ & $0.181^{\mathrm{b}}$ \\
\hline Onset year (year) & $66.32 \pm 8.80$ & $64.10 \pm 8.55$ & $0.162^{a}$ \\
\hline Current smoking (number/percentage) & $30 / 33.3 \%$ & $6 / 20.7 \%$ & $0.249^{\mathrm{C}}$ \\
\hline Degree of education (year) & $11.90 \pm 2.53$ & $12.00 \pm 2.36$ & $0.795^{\mathrm{b}}$ \\
\hline \multicolumn{4}{|l|}{ Form of onset } \\
\hline Tremor (number/percentage) & $42 / 46.7 \%$ & $14 / 48.3 \%$ & $1.000^{\mathrm{C}}$ \\
\hline Dominant side involved (number/percentage) & $49 / 54.4 \%$ & $17 / 58.6 \%$ & $0.830^{\circ}$ \\
\hline \multicolumn{4}{|l|}{ Drugs } \\
\hline Levodopa intake (number/percentage) & $81 / 90.0 \%$ & $29 / 100 \%$ & $0.111^{\mathrm{C}}$ \\
\hline MAOBI (number/percentage) & $17 / 18.9 \%$ & $5 / 17.2 \%$ & $1.000^{\mathrm{C}}$ \\
\hline COMTI (number/percentage) & $3 / 3.3 \%$ & $1 / 3.4 \%$ & $1.000^{\circ}$ \\
\hline \multicolumn{4}{|l|}{ Movement symptoms } \\
\hline UPDRS-III & $20.66 \pm 12.06$ & $19.93 \pm 10.22$ & $0.995^{b}$ \\
\hline H\&Y & & & $0.861^{\mathrm{c}}$ \\
\hline 0-1 (number/percentage) & $32 / 35.6 \%$ & $9 / 31.0 \%$ & \\
\hline 1.5-2 (number/percentage) & $37 / 41.1 \%$ & $12 / 41.4 \%$ & \\
\hline 2.5-3 (number/percentage) & $21 / 23.3 \%$ & $8 / 27.6 \%$ & \\
\hline
\end{tabular}

HbA1C, glycosylated hemoglobin A1c; DRA, dopamine receptor agnoists; MAOBI, Monoamine oxidase type B inhibitors; COMTI, Catechol-O-methyltransferase inhibitors; UPDRS-III, Unified Parkinson's Disease Rating Scale motor score, H-Y staging, Hohen-Yahr staging; atwo-sample t- test; ${ }^{\mathrm{b}}$ Mann-Whitney U-test; ${ }^{\circ}$ Chi-square test. 


\section{RESULTS}

\section{Clinical Characteristics of PD-DM and PD-nDM Patients}

A total of $282 \mathrm{PD}$ patients were recruited in this study, 85 of them with DM (30.1\%) (PD-DM) and 197 of them without diabetes (69.9\%) (PD-nDM). As shown in Table 1, there was no significant difference in age, gender, education, levodopa equivalent dosage, various types of drug ratio, onset age, duration, onset form, UPDRS-III, H-Y staging, HAMA score, or HAMD score between PD-DM and PD-nDM groups. Body mass index (BMI) in PD$\mathrm{DM}$ group was significantly higher than that in $\mathrm{PD}-\mathrm{nDM}$ group $\left(23.17 \pm 1.57\right.$ vs. $\left.22.56 \pm 2.28 \mathrm{~kg} / \mathrm{m}^{2}, p=0.010\right)$ (Table 1). Interestingly, MoCA score $(23.35 \pm 3.41$ vs. $25.12 \pm 2.99$, $p=0.000)$ and MMSE score $(27.32 \pm 2.28$ vs. $28.18 \pm 1.74$, $p=0.003)$ in $\mathrm{PD}-\mathrm{DM}$ group were significantly lower than those in PD-nDM group (Figure 1A). In addition, PD-DM group showed significantly higher constituent ratio of CI compared to PD-nDM group $(\mathrm{x} 2=21.400, p=0.000)$ (Table 2$)$.

\section{Comparison of Cognitive Function at Different Levels of HbA1c and Insulin Resistance in Parkinson's Disease Patients}

In our current study, HbAlc and HOMA-index were used as parameters to evaluate diabetes control and insulin resistance in PD, respectively. As shown in Figures 1B,C, MoCA scores in $\mathrm{HbAlc} \geq 6.5 \%$ group $(24.41 \pm 0.91$ vs. $26.02 \pm 2.21$, $p=0.016)$ and $\mathrm{HbA1c} \geq 7 \%$ group $(24.96 \pm 1.85$ vs. $26.03 \pm 2.21, p=0.007)$ were significantly lower than those in the corresponding control groups. Furthermore, MoCA score in IR $\geq 3$ group was significantly lower than that in IR $<3$ group ( $24.93 \pm 1.58$ vs. $25.94 \pm 2.23, p=0.049)$ (Figure 1D). In addition, none of $\mathrm{HbAlc} \geq 6.5 \%, \mathrm{HbA} 1 \mathrm{c} \geq 7 \%$ or $\mathrm{IR} \geq 3$ groups showed significant difference in age, gender, education, levodopa equivalent dosage, drug ratio, onset age, duration, onset form, UPDRS-III, H-Y staging, MMSE score, HAMA score, or HAMD score compared with the corresponding control groups (Tables 3-5).

\section{Risk Factors of Cognitive Impairment in Parkinson's Disease}

As shown in Table 6, MoCA score was negatively correlated with $\mathrm{H}-\mathrm{Y}$ staging $(r=-0.243, p=0.008)$, HbAlc $(r=-0.207$, $p=0.024)$, and insulin resistance $(r=-0.498, p=0.000)$. However, MMSE score had no correlation with either $\mathrm{H}-\mathrm{Y}$ staging or glucose metabolic indicators (Table 6). To identify the risk factors of $\mathrm{CI}$, logistic regression analysis was conducted, and our data indicated that $\mathrm{H}-\mathrm{Y}$ staging $(\mathrm{OR}=1.844,95 \%$ confidence interval:1.162 2.927, $p=0.009)$ and HbAlc $\geq 7 \%$ $(\mathrm{OR}=4.253,95 \%$ confidence interval:1.596 11.342, $p=0.004)$ were independent risk factors of CI in patients with PD (Table 7).

TABLE 4 | Clinical characteristics of $\mathrm{HbA} 1 \mathrm{c}<7$ and $\mathrm{HbA} 1 \mathrm{c} \geq 7$ groups in PD.

\begin{tabular}{|c|c|c|c|}
\hline & $\begin{array}{c}\mathrm{HbA} 1 \mathrm{c}<7 \\
(n=95)\end{array}$ & $\begin{array}{c}\mathrm{HbA} 1 \mathrm{c} \geq 7 \\
(n=24)\end{array}$ & $P$ \\
\hline Gender (male: number/percentage) & $55 / 57.9 \%$ & $11 / 45.8 \%$ & $0.360^{c}$ \\
\hline Age (year) & $70.41 \pm 7.71$ & $68.54 \pm 7.54$ & $0.239^{a}$ \\
\hline Duration (year) & $4.17 \pm 3.05$ & $4.28 \pm 4.17$ & $0.578^{b}$ \\
\hline Onset year (year) & $66.13 \pm 8.64$ & $64.38 \pm 9.23$ & $0.303^{a}$ \\
\hline Current smoking (number/percentage) & $31 / 32.6 \%$ & $5 / 20.8 \%$ & $0.326^{c}$ \\
\hline Body mass index (BMl, $\left.\mathrm{Kg} / \mathrm{m}^{2}\right)$ & $22.73 \pm 1.37$ & $23.18 \pm 1.67$ & $0.156^{a}$ \\
\hline Degree of education (year) & $12.01 \pm 2.53$ & $11.58 \pm 2.26$ & $0.509^{b}$ \\
\hline \multicolumn{4}{|l|}{ Form of onset } \\
\hline Tremor (number/percentage) & $44 / 46.3 \%$ & $12 / 50.0 \%$ & $0.821^{c}$ \\
\hline Dominant side involved (number/percentage) & $51 / 53.7 \%$ & $15 / 62.5 \%$ & $0.496^{c}$ \\
\hline \multicolumn{4}{|l|}{ Drugs } \\
\hline levodopa equivalent dosage (mg/day) & $503.29 \pm 298.44$ & $419.79 \pm 153.40$ & $0.286^{a}$ \\
\hline levodopa dosage (mg/day) & $441.05 \pm 268.17$ & $368.75 \pm 153.09$ & $0.370^{\mathrm{a}}$ \\
\hline DRA (number/percentage) & $43 / 45.3 \%$ & $11 / 45.8 \%$ & $1.000^{c}$ \\
\hline MAOBI (number/percentage) & $19 / 20.0 \%$ & $3 / 12.5 \%$ & $0.560^{\mathrm{C}}$ \\
\hline COMTI (number/percentage) & $4 / 4.2 \%$ & 0 & $0.582^{\mathrm{C}}$ \\
\hline \multicolumn{4}{|l|}{ Movement symptoms } \\
\hline UPDRS-III & $20.64 \pm 11.79$ & $19.83 \pm 11.03$ & $0.827^{b}$ \\
\hline$H \& Y$ & & & $0.840^{\mathrm{C}}$ \\
\hline 0-1 (number/percentage) & $33 / 34.7 \%$ & $8 / 33.3 \%$ & \\
\hline 1.5-2 (number/percentage) & $40 / 42.1 \%$ & $9 / 37.5 \%$ & \\
\hline 2.5-3 (number/percentage) & $22 / 23.2 \%$ & $7 / 29.2 \%$ & \\
\hline
\end{tabular}

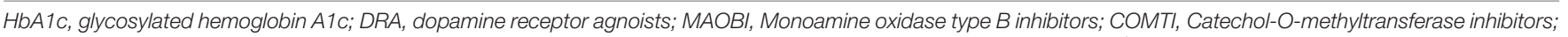
UPDRS-III, Unified Parkinson's Disease Rating Scale motor score; H-Y staging, Hohen-Yahr staging; ' two-sample t- test; ${ }^{\mathrm{b}}$ Mann-Whitney U-test; ' ${ }^{\circ}$ Chi-square test. 
TABLE 5 | Clinical characteristics of $I R<3$ and $I R \geq 3$ groups in PD.

\begin{tabular}{|c|c|c|c|}
\hline & $\begin{array}{c}\text { IR }<3 \\
(n=104)\end{array}$ & $\begin{array}{c}I R \geq 3 \\
(n=15)\end{array}$ & $P$ \\
\hline Gender (male: number/percentage) & $58 / 55.8 \%$ & $8 / 53.3 \%$ & $0.859^{c}$ \\
\hline Age (year) & $70.23 \pm 7.54$ & $68.67 \pm 7.79$ & $0.532^{\mathrm{a}}$ \\
\hline Duration (year) & $4.18 \pm 4.08$ & $4.73 \pm 3.04$ & $0.215^{\mathrm{b}}$ \\
\hline Onset year (year) & $66.04 \pm 8.53$ & $63.93 \pm 10.31$ & $0.374^{a}$ \\
\hline Current smoking (number/percentage) & $33 / 31.7 \%$ & $3 / 20.0 \%$ & $0.394^{\mathrm{C}}$ \\
\hline Body mass index (BMl, $\left.\mathrm{Kg} / \mathrm{m}^{2}\right)$ & $22.73 \pm 1.42$ & $23.18 \pm 1.67$ & $0.578^{a}$ \\
\hline Degree of education (year) & $11.93 \pm 2.56$ & $11.87 \pm 1.92$ & $0.922^{b}$ \\
\hline \multicolumn{4}{|l|}{ Form of onset } \\
\hline Tremor (number/percentage) & $49 / 47.1 \%$ & $7 / 46.7 \%$ & $1.000^{\mathrm{C}}$ \\
\hline Dominant side involved (number/percentage) & $57 / 54.8 \%$ & $9 / 60.0 \%$ & $0.786^{\mathrm{c}}$ \\
\hline \multicolumn{4}{|l|}{ Drugs } \\
\hline Levodopa equivalent dosage (mg/day) & $480.65 \pm 280.49$ & $526.67 \pm 255.73$ & $0.482^{a}$ \\
\hline Levodopa dosage (mg/day) & $424.52 \pm 257.32$ & $440.00 \pm 202.84$ & $0.275^{a}$ \\
\hline DRA (number/percentage) & $48 / 46.2 \%$ & $6 / 11.1 \%$ & $0.784^{\mathrm{C}}$ \\
\hline MAOBI (number/percentage) & $18 / 17.3 \%$ & $4 / 26.7 \%$ & $0.475^{\mathrm{C}}$ \\
\hline COMTI (number/percentage) & $4 / 3.8 \%$ & 0 & $1.000^{\mathrm{C}}$ \\
\hline \multicolumn{4}{|l|}{ Movement symptoms } \\
\hline UPDRS-III & $19.97 \pm 11.37$ & $24.00 \pm 12.96$ & $0.220^{b}$ \\
\hline $\mathrm{H} \& Y$ & & & $0.647^{c}$ \\
\hline 0-1 (number/percentage) & $37 / 35.6 \%$ & $4 / 26.7 \%$ & \\
\hline 1.5-2 (number/percentage) & $41 / 39.4 \%$ & $8 / 53.3 \%$ & \\
\hline 2.5-3 (number/percentage) & $26 / 25.0 \%$ & $3 / 20.0 \%$ & \\
\hline
\end{tabular}

IR, insulin resistance; DRA, dopamine receptor agnoists; MAOBI, Monoamine oxidase type B inhibitors; COMTI, Catechol-O-methyltransferase inhibitors; UPDRS-III, Unified Parkinson's Disease Rating Scale motor score; H-Y staging, Hohen-Yahr staging; a two-sample t- test; ${ }^{\mathrm{b}}$ Mann-Whitney U-test; ${ }^{\mathrm{c}} \mathrm{Chi}$-square test.

\section{DISCUSSION}

In this study, we investigated clinical features of PD patients with or without dysglycemia, examined risk factors of CI in PD, and

TABLE 6 | Correlation of $\mathrm{Cl}$ with $\mathrm{H}-\mathrm{Y}$ staging, $\mathrm{HbA} 1 \mathrm{c}$ and IR in PD.

\begin{tabular}{lccrccc}
\hline & \multicolumn{3}{c}{ MMSE } & & \multicolumn{3}{c}{ MoCA } \\
\cline { 2 - 3 } \cline { 5 - 6 } & $\boldsymbol{r}$ & $\boldsymbol{P}$ & & $\boldsymbol{r}$ & $\boldsymbol{P}$ \\
\hline H-Y staging & -0.070 & $0.448^{\mathrm{d}}$ & & -0.243 & $\mathbf{0 . 0 0 8}^{\mathrm{d}}$ \\
HbA1C & -0.114 & $0.218^{\mathrm{d}}$ & & -0.207 & $\mathbf{0 . 0 2 4}^{\mathrm{d}}$ \\
IR & -0.027 & $0.772^{\mathrm{d}}$ & & -0.498 & $\mathbf{0 . 0 0 0}^{\mathrm{d}}$
\end{tabular}

MMSE, Mini Mental State Examination; MoCA, Montreal Cognitive Assessment; $H-Y$ staging, Hohen-Yahr staging; HbA1C, serum glycosylated hemoglobin A1C; $I R$, insulin resistance; ${ }^{d}$ spearman correlation analysis.

TABLE 7 | Regression analysis on risk factors of $\mathrm{Cl}$ in PD.

\begin{tabular}{lccccc}
\hline & $\boldsymbol{B}$ & SE & $\boldsymbol{P}$ & OR & $\mathbf{9 5 \% \mathbf { C l }}$ \\
\hline $\mathrm{H}-\mathrm{Y}$ staging & 0.612 & 0.236 & $\mathbf{0 . 0 0 9}$ & 1.844 & $(1.162 \sim 2.927)$ \\
$\mathrm{HbA} 1 \mathrm{C} \geq 7 \%$ & 1.448 & 0.500 & $\mathbf{0 . 0 0 4}$ & 4.253 & $(1.596 \sim 11.342)$ \\
$\mathrm{HbA} 1 \mathrm{C} \geq 6.5 \%$ & 0.044 & 1.059 & $0.967^{\mathrm{e}}$ & 1.045 & $(0.131 \sim 8.329)$ \\
$\mathrm{IR} \geq 3$ & 0.508 & 0.768 & $0.509^{\mathrm{e}}$ & 0.369 & $(0.777 \sim 14.279)$
\end{tabular}

H-Y staging, Hohen-Yahr staging; HbA1c, serum glycosylated hemoglobin A1C; IR, insulin resistance; elogistic regression analysis. explored the relationship between CI and dysglycemia in patients with PD.

Cognitive impairment is frequently found in $\mathrm{PD}$, especially in the late stage of the disease (Hely et al., 2008; Aarsland et al., 2010; Litvan et al., 2011). It is well known that diabetes is one of the risk factors of cognitive dysfunction ( $\mathrm{Xu}$ et al., 2009) in several diseases, but it remains unclear about the role of dysglycemia in CI of PD. In the present study, we observed that PD-DM patients had significant higher BMI compared to $\mathrm{PD}-\mathrm{nDM}$ patients, which was in accordance with the clinical features of DM (Hu et al., 2004). There was no significant difference in onset form, dominant side involvement, levodopa equivalent dosage, doses of levodopa, UPDRS-III, or $\mathrm{H}-\mathrm{Y}$ staging between PD-DM and PD-nDM patients. However, previous studies have suggested PD patients with diabetes may have worse motor symptoms compared to those without diabetes. A case-control study indicated that patients with PD and DM had higher motor scores, and needed larger doses of dopaminergic treatment compared to patients with PD only (Cereda et al., 2012). Another cohort study showed that diabetes could aggravate the movement symptoms of $\mathrm{PD}$, especially gait disturbance and postural stability (Kotagal et al., 2013). The disparity between our results and other studies may be due to the difference of sample size and enrolled patient population. In line with the previous study (Profenno et al., 2010), our data showed significant differences in MMSE and MoCA scores were observed between PD-DM and PD-nDM patients. Moreover, the prevalence of cognitive dysfunction is significantly higher 
in $\mathrm{PD}-\mathrm{DM}$ patients than that in $\mathrm{PD}-\mathrm{nDM}$ patients, suggesting that diabetes may be one risk factor for cognitive dysfunction in, at least partially, PD patients. It has been shown that $\alpha$ synuclein, amyloid- $\beta(A \beta)$ peptides, and tau protein may be involved in the pathologic process of CI in PD (Weintraub et al., 2012; Kang et al., 2013). Laboratory studies suggested that CI was caused by aberrant glycation of $\alpha$-synuclein, $A \beta$ peptides and tau protein (Vicente Miranda et al., 2016), which was induced by glycation agent produced by dysglycemia (Sousa Silva et al., 2013). Insulin resistance may also lead to the abnormal regulation of tau, resulting in $A \beta$ peptides deposition (Bosco et al., 2011). It is necessary to further investigate the specific pathological mechanism for $\mathrm{CI}$ in $\mathrm{PD}$ in our future research.

HbA1c, a commonly used parameter reflecting the mean glucose concentration during the past 8-12 weeks, is a superior indicator to assess long-term glycemic control (Miedema, 2005). Although several methods have been developed to diagnose human insulin resistance, the HOMA-index method has been recognized as the mostly employed approach in both clinical practice and epidemiological studies due to its simplicity (Matthews et al., 1985; Salgado et al., 2010). Therefore, in our current study, HbA1c and HOMA-index were used as parameters to evaluate diabetes control and insulin resistance in $\mathrm{PD}$, respectively. We observed that MoCA scores in $\mathrm{HbA1c} \geq 6.5 \%$, $\mathrm{HbAlc} \geq 7 \%$ and insulin resistance $\geq 3$ groups were significantly lower than that in the corresponding control groups, suggesting $\mathrm{CI}$ is associated with the control situation of diabetes in, at least partially, PD patients. In our study, $\mathrm{HbA1c} \geq 6.5, \mathrm{HbA} 1 \mathrm{c} \geq 7$ and IR $\geq 3$ groups were significantly lower than the corresponding control groups, which is in agreement with actual clinical conditions and also observed in previous studies (Bohnen et al., 2014; Ong et al., 2017).

Furthermore, correlation analysis showed MoCA score was negatively correlated with $\mathrm{H}-\mathrm{Y}$ staging, $\mathrm{HbAlc}$ and insulin resistance, respectively. However, MMSE score was not correlated with either $\mathrm{H}-\mathrm{Y}$ staging or glucose metabolic indicators. The potential reason could be that MoCA has the higher sensitivity and specificity (Dalrymple-Alford et al., 2010), better evaluation reliability (Gill et al., 2008), and higher discriminant validity (Hoops et al., 2009) in the assessment of cognitive function in PD, whereas there is a ceiling effect of MMSE in cognitive evaluation (Hoops et al., 2009; Marras et al., 2013). Based on the previous studies (Dalrymple-Alford et al., 2010; Litvan et al., 2012; Marras et al., 2013), we set MoCA 26' as a discriminator to differentiate CI, which was shown to be a convenience and reliable approach for clinicians to evaluate patients' cognitive function.

Finally, logistic regression analysis showed that $\mathrm{H}-\mathrm{Y}$ staging and $\mathrm{HbAlc} \geq 7 \%$ were risk factors of $\mathrm{CI}$ in $\mathrm{PD}$. The correlation of $\mathrm{CI}$ with $\mathrm{H}-\mathrm{Y}$ staging is in accordance with the development characteristics of PD. With the progression of disease severity, cognitive dysfunction gradually deteriorated (Hely et al., 2008). Among all the glucose metabolic indicators, $\mathrm{HbAlc} \geq 7 \%$ was a significant risk factor of CI in PD. Some large scale crosssectional (Cukierman-Yaffe et al., 2009; Nguyen et al., 2010) and prospective studies (Kanaya et al., 2004; Yaffe et al., 2006, 2012) have indicated that lower score of MoCA is associated with higher level of HbA1c. The American Diabetes Association (ADA) proposed that $\mathrm{HbAlc} \geq 6.5 \%$ can be used to diagnose DM, and keeping an HbA1c lower than 7\% reduces the occurrence of diabetic microvascular lesion (Yaffe et al., 2012). Based on our study and previous studies, H-Y staging and HbAlc may serve as key parameters for controlling CI in PD clinical practice.

There are still some limitations in this study. First of all, the sample size of our study was relatively small, and the participants were mainly from Shanghai, China, therefore, our results may have a certain area or racial bias. Secondly, our study was a cross-sectional research, lacking of comparative support from prospective study. Thirdly, our study lacked cerebral vascular disease risk factors (such as drinking, hypertension, stroke) assessment, and there was no further analysis of the influence of diabetic medicines on patients' cognitive function. Lastly, all the patients participated in our study had a $\mathrm{H}-\mathrm{Y}$ staging 3 or less than 3 , namely early stage PD patients. Therefore, our results may not apply to the whole PD group.

\section{CONCLUSION}

Our study showed that CI may be tightly associated with dysglycemia in, at least partially, PD patients. Importantly, $\mathrm{H}-\mathrm{Y}$ staging and $\mathrm{HbA} 1 \mathrm{c} \geq 7 \%$ may be independent risk factors of $\mathrm{CI}$ in PD, and may serve as key biomarkers in future PD clinical practice. Further studies are needed to investigate the specific mechanism for CI of PD.

\section{AUTHOR CONTRIBUTIONS}

XW conceived the project and designed the study. LYa, ZC, and $\mathrm{BL}$ contributed to participant recruitment, data collection and data analysis. MW and LYu contributed to participant recruitment and data collection. YW, JG, YZ, and ZL contributed to supervise the study. LYa, BL, and XW wrote the paper together.

\section{FUNDING}

This work was supported by the Projects of the National Natural Science Foundation of China (Nos. 81671273, 81171204, 30772280, 81400925, 81471148, 81771211, and 81703852), the Project of Shanghai Municipal Education Commission of China (No. 14YZ046), the Project of Shanghai Municipal Health and Family Planning Commission of China (No. 20134049), the Project of Shanghai Jiao Tong University of China (No. YG2013MS22), the Project of National Eastern Tech-transfer Center (201713972877), and the Projects of Shanghai Committee of Science and Technology (17401901000), National key R\&D Program of China (2017YFC1310300), SHSMU-ION Research Center for Brain Disorders (2015NKX007). 


\section{REFERENCES}

Aarsland, D., Andersen, K., Larsen, J. P., Lolk, A., Nielsen, H., and KraghSorensen, P. (2001). Risk of dementia in Parkinson's disease: a communitybased, prospective study. Neurology 56, 730-736. doi: 10.1212/WNL.56. 6.730

Aarsland, D., Bronnick, K., Williams-Gray, C., Weintraub, D., Marder, K., Kulisevsky, J., et al. (2010). Mild cognitive impairment in Parkinson disease: a multicenter pooled analysis. Neurology 75, 1062-1069. doi: 10.1212/WNL. 0b013e3181f39d0e

Bohnen, N. I., Kotagal, V., Müller, M. L., Koeppe, R. A., Scott, P. J., Albin, R. L., et al. (2014). Diabetes mellitus is independently associated with more severe cognitive impairment in Parkinson disease. Parkinsonism Relat. Disord. 20, 1394-1398. doi: 10.1016/j.parkreldis.2014.10.008

Boon, A., Lodder, J., Cheriex, E., and Kessels, F. (1997). Mitral annulus calcification is not an independent risk factor for stroke: a cohort study of 657 patients. J. Neurol. 244, 535-541. doi: 10.1007/s004150050140

Bosco, D., Fava, A., Plastino, M., Montalcini, T., and Pujia, A. (2011). Possible implications of insulin resistance and glucose metabolism in Alzheimer's disease pathogenesis. J. Cell Mol. Med. 15, 1807-1821. doi: 10.1111/j.1582-4934.2011. 01318.x

Bosco, D., Plastino, M., Cristiano, D., Colica, C., Ermio, C., De Bartolo, M., et al. (2012). Dementia is associated with insulin resistance in patients with Parkinson's disease. J. Neurol. Sci. 315, 39-43. doi: 10.1016/j.jns.2011. 12.008

Cereda, E., Barichella, M., Cassani, E., Caccialanza, R., and Pezzoli, G. (2012). Clinical features of Parkinson disease when onset of diabetes came first: a case-control study. Neurology 78, 1507-1511. doi: 10.1212/WNL.0b013e31825 $53 \operatorname{cc} 9$

Cereda, E., Barichella, M., Pedrolli, C., Klersy, C., Cassani, E., Caccialanza, R., et al. (2011). Diabetes and risk of Parkinson's disease: a systematic review and meta-analysis. Diabetes Care 34, 2614-2623. doi: 10.2337/dc111584

Cukierman-Yaffe, T., Gerstein, H. C., Williamson, J. D., Lazar, R. M., Lovato, L., Miller, M. E., et al. (2009). Relationship between baseline glycemic control and cognitive function in individuals with type 2 diabetes and other cardiovascular risk factors: the action to control cardiovascular risk in diabetes-memory in diabetes (ACCORD-MIND) trial. Diabetes Care 32, 221-226. doi: 10.2337/ dc08- 1153

Dalrymple-Alford, J. C., Macaskill, M. R., Nakas, C. T., Livingston, L., Graham, C., Crucian, G. P., et al. (2010). The MoCA: well-suited screen for cognitive impairment in Parkinson disease. Neurology 75, 1717-1725. doi: 10.1212/WNL. 0b013e3181fc29c9

Gill, D. J., Freshman, A., Blender, J. A., and Ravina, B. (2008). The Montreal cognitive assessment as a screening tool for cognitive impairment in Parkinson's disease. Mov. Disord. 23, 1043-1046. doi: 10.1002/mds.22017

Hamilton, M. (1967). Development of a rating scale for primary depressive illness. Br. J. Soc. Clin. Psychol. 6, 278-296. doi: 10.1111/j.2044-8260.1967.tb00530.x

Hely, M. A., Reid, W. G., Adena, M. A., Halliday, G. M., and Morris, J. G. (2008). The Sydney multicenter study of Parkinson's disease: the inevitability of dementia at 20 years. Mov. Disord. 23, 837-844. doi: 10.1002/mds.21956

Hoops, S., Nazem, S., Siderowf, A. D., Duda, J. E., Xie, S. X., Stern, M. B., et al. (2009). Validity of the MoCA and MMSE in the detection of MCI and dementia in Parkinson disease. Neurology 73, 1738-1745. doi: 10.1212/WNL. 0b013e3181c34b47

Hu, G., Lindstrom, J., Valle, T. T., Eriksson, J. G., Jousilahti, P., Silventoinen, K., et al. (2004). Physical activity, body mass index, and risk of type 2 diabetes in patients with normal or impaired glucose regulation. Arch. Intern. Med. 164, 892-896. doi: 10.1001/archinte.164.8.892

Kanaya, A. M., Barrett-Connor, E., Gildengorin, G., and Yaffe, K. (2004). Change in cognitive function by glucose tolerance status in older adults: a 4-year prospective study of the Rancho Bernardo study cohort. Arch. Intern. Med. 164, 1327-1333. doi: 10.1001/archinte.164.12.1327

Kandiah, N., Zhang, A., Cenina, A. R., Au, W. L., Nadkarni, N., and Tan, L. C. (2014). Montreal Cognitive Assessment for the screening and prediction of cognitive decline in early Parkinson's disease. Parkinsonism Relat. Disord. 20, 1145-1148. doi: 10.1016/j.parkreldis.2014.08.002
Kang, J. H., Irwin, D. J., Chen-Plotkin, A. S., Siderowf, A., Caspell, C., Coffey, C. S., et al. (2013). Association of cerebrospinal fluid beta-amyloid 1-42, T-tau, P-tau181, and alpha-synuclein levels with clinical features of drug-naive patients with early Parkinson disease. JAMA Neurol. 70, 1277-1287.

Kotagal, V., Albin, R. L., Muller, M. L., Koeppe, R. A., Frey, K. A., and Bohnen, N. I. (2013). Diabetes is associated with postural instability and gait difficulty in Parkinson disease. Parkinsonism Relat. Disord. 19, 522-526. doi: 10.1016/j. parkreldis.2013.01.016

Litvan, I., Aarsland, D., Adler, C. H., Goldman, J. G., Kulisevsky, J., Mollenhauer, B., et al. (2011). MDS Task Force on mild cognitive impairment in Parkinson's disease: critical review of PD-MCI. Mov. Disord. 26, 1814-1824. doi: 10.1002/ mds. 23823

Litvan, I., Goldman, J. G., Troster, A. I., Schmand, B. A., Weintraub, D., Petersen, R. C., et al. (2012). Diagnostic criteria for mild cognitive impairment in Parkinson's disease: movement disorder society task force guidelines. Mov. Disord. 27, 349-356. doi: 10.1002/mds.24893

Marras, C., Armstrong, M. J., Meaney, C. A., Fox, S., Rothberg, B., Reginold, W., et al. (2013). Measuring mild cognitive impairment in patients with Parkinson's disease. Mov. Disord. 28, 626-633. doi: 10.1002/mds.25426

Matthews, D. R., Hosker, J. P., Rudenski, A. S., Naylor, B. A., Treacher, D. F., and Turner, R. C. (1985). Homeostasis model assessment: insulin resistance and beta-cell function from fasting plasma glucose and insulin concentrations in man. Diabetologia 28, 412-419. doi: 10.1007/BF0028 0883

Miedema, K. (2005). Standardization of HbAlc and optimal range of monitoring. Scand. J. Clin. Lab. Invest. Suppl. 240, 61-72. doi: 10.1080/00365510500236143

Nguyen, H. T., Grzywacz, J. G., Arcury, T. A., Chapman, C., Kirk, J. K., Ip, E. H., et al. (2010). Linking glycemic control and executive function in rural older adults with diabetes mellitus. J. Am. Geriatr. Soc. 58, 1123-1127. doi: 10.1111/j. 1532-5415.2010.02857.x

Ong, M., Foo, H., Chander, R. J., Wen, M. C., Au, W. L., Sitoh, Y. Y., et al. (2017). Influence of diabetes mellitus on longitudinal atrophy and cognition in Parkinson's disease. J. Neurol. Sci. 377, 122-126. doi: 10.1016/j.jns.2017.04.010

Profenno, L. A., Porsteinsson, A. P., and Faraone, S. V. (2010). Meta-analysis of Alzheimer's disease risk with obesity, diabetes, and related disorders. Biol. Psychiatry 67, 505-512. doi: 10.1016/j.biopsych.2009.02.013

Salgado, A. L., Carvalho, L. D., Oliveira, A. C., Santos, V. N., Vieira, J. G., and Parise, E. R. (2010). Insulin resistance index (HOMA-IR) in the differentiation of patients with non-alcoholic fatty liver disease and healthy individuals. Arq. Gastroenterol. 47, 165-169. doi: 10.1590/S0004-280320100002 00009

Sousa Silva, M., Gomes, R. A., Ferreira, A. E., Ponces Freire, A., and Cordeiro, C. (2013). The glyoxalase pathway: the first hundred years... and beyond. Biochem. J. 453, 1-15. doi: 10.1042/BJ20121743

Vicente Miranda, H., El-Agnaf, O. M., and Outeiro, T. F. (2016). Glycation in Parkinson's disease and Alzheimer's disease. Mov. Disord. 31, 782-790. doi: $10.1002 / \mathrm{mds} .26566$

Weintraub, D., Dietz, N., Duda, J. E., Wolk, D. A., Doshi, J., Xie, S. X., et al. (2012). Alzheimer's disease pattern of brain atrophy predicts cognitive decline in Parkinson's disease. Brain 135(Pt 1), 170-180. doi: 10.1093/brain/ awr277

Xiao, Z., Wang, J., Zhang, M., Li, H., Tang, Y., Wang, Y., et al. (2011). Errorrelated negativity abnormalities in generalized anxiety disorder and obsessivecompulsive disorder. Prog. Neuropsychopharmacol. Biol. Psychiatry 35, 265-272. doi: 10.1016/j.pnpbp.2010.11.022

Xu, W., Qiu, C., Gatz, M., Pedersen, N. L., Johansson, B., and Fratiglioni, L. (2009). Mid- and late-life diabetes in relation to the risk of dementia: a populationbased twin study. Diabetes Metab. Res. Rev. 58, 71-77. doi: 10.2337/db080586

Xu, Y., Wang, L., He, J., Bi, Y., Li, M., Wang, T., et al. (2013). Prevalence and control of diabetes in Chinese adults. JAMA 310, 948-959. doi: 10.1001/jama. 2013.168118

Yaffe, K., Blackwell, T., Whitmer, R. A., Krueger, K., and Barrett Connor, E. (2006). Glycosylated hemoglobin level and development of mild cognitive impairment or dementia in older women. J. Nutr. Health Aging 10, 293-295. 
Yaffe, K., Falvey, C., Hamilton, N., Schwartz, A. V., Simonsick, E. M., Satterfield, S., et al. (2012). Diabetes, glucose control, and 9-year cognitive decline among older adults without dementia. Arch. Neurol. 69, 1170-1175. doi: 10.1001/ archneurol.2012.1117

Conflict of Interest Statement: The authors declare that the research was conducted in the absence of any commercial or financial relationships that could be construed as a potential conflict of interest.
Copyright (c) 2017 Yang, Chen, Li, Wang, Yu, Wan, Gan, Zhang, Liu and Wang. This is an open-access article distributed under the terms of the Creative Commons Attribution License (CC BY). The use, distribution or reproduction in other forums is permitted, provided the original author(s) or licensor are credited and that the original publication in this journal is cited, in accordance with accepted academic practice. No use, distribution or reproduction is permitted which does not comply with these terms. 